\title{
Effect of sodium chenodeoxycholate on oxalate absorption from the excluded human colon- a mechanism for 'enteric' hyperoxaluria
}

\author{
P. D. FAIRCLOUGH, T. G. FEEST, V. S. CHADWICK, AND M. L. CLARK ${ }^{1}$
}

From the Department of Gastroenterology, St. Bartholomew's Hospital, London

SUMMARY A perfusion technique has been used to study the effect of sodium chenodeoxycholate $\left(5 \mathrm{mmol}^{-1}\right)$ on absorption of oxalate $\left(2 \mathrm{mmol}^{-1}\right)$ from the surgically excluded colon in two patients with chronic liver disease. Colonic absorption of oxalate increased at least fivefold when sodium chenodeoxycholate was incorporated in the perfusion solutions. This observation may explain enteric hyperoxaluria after ileal resection and in some other gastrointestinal disorders.

Clinically significant secondary hyperoxaluria, resulting in the formation of oxalate stones in the urinary tract, occurs after ileal resection (Smith et al., 1970; Dowling et al., 1971) and jejunoileal bypass (Dickstein and Frame, 1973; O'Leary et al., 1974), in patients with severe ileal disease (Admirand $e t$ al., 1971; Smith et al., 1972), pancreatic exocrine insufficiency (Stauffer et al., 1974), and coeliac disease (McDonald et al., 1975).

The origin of this 'enteric' hyperoxaluria has been shown to be excessive absorption of dietary oxalate (Chadwick et al., 1973; Stauffer et al., 1973; Earnest et al., 1974). Neither the site nor the mechanism of the increase in oxalate absorption is known, although it is thought that the colon may play an important role because patients with ileal resection and ileostomy or colectomy do not develop hyperoxaluria (Earnest et al., 1974; O'Leary et al., 1974).

After an ileal resection, excessive quantities of bile acids enter the colon because the normal ileal recapture mechanism has been removed. These bile acids, as well as inducing diarrhoea due to colonic secretion of water and electrolytes (Mekhjian et al., 1971) may also affect absorption of other substances from the colon. In the present study we have therefore tested the effect of an unconjugated bile saltsodium chenodeoxycholate-on colonic oxalate absorption in man, using a perfusion technique in two subjects with colonic exclusion. Absorption of

${ }^{1}$ Address for correspondence: Dr M. L. Clark, Department of Gastroenterology, St. Bartholomew's Hospital, London EC1A 7BE

Accepted for publication 28 September 1976 sodium oxalate from a $2 \mathrm{mmol}^{-1}$ solution has been studied, since this seems likely to be within the range encountered in the normal human colon. Although normal faecal fluid contains only trace amounts of bile salt, the faecal fluid of patients after ileal resection may contain up to $13 \mathrm{mmol} \mathrm{l}^{-1}$ (Hofmann and Poley, 1972; Mitchell et al., 1973). We have therefore studied the effect of a model bile salt at a concentration of $5 \mathrm{mmoll}^{-1}$.

\section{Methods}

The two subjects were aged 38 and 67 years and had undergone portocaval anastomosis for relief of portal hypertension 13 and 24 years before the present study. Colonic exclusion was performed for the treatment of disabling chronic hepatic encephalopathy (McDermott et al., 1962) five and $1 \frac{1}{2}$ years before the study. Both subjects were well; one is in full-time employment as a school caretaker and the other enjoys an active agricultural retirement. The subjects gave fully informed consent to the study procedures.

Perfusion studies were performed at least eight hours after the last meal, but unlimited clear fluids were allowed to maintain normal hydration. The perfusion procedure was as described by Bown $e t$ al. (1972). Solutions were perfused anti-peristaltically (because this produces a steadier flow of effluent) at $10 \mathrm{ml} \mathrm{min}-1$. A two hour equilibration period was allowed before the collection of four consecutive 10 minute samples of intestinal effluent. The $\mathrm{pH}$ of each solution was immediately measured and after filtration through glass wool to remove mucus, 
Table 1 Composition of perfusion solutions

\begin{tabular}{llllllllll}
\hline Solution & $\mathrm{Na}^{+}$ & $\mathrm{K}^{+}$ & $\mathrm{Cl}^{-}$ & $\mathrm{HPO}^{2}-$ & $\mathrm{H}_{2} \mathrm{PO}_{4}^{-}$ & Oxalate & $\mathrm{CDC}$ & $\mathrm{pH}$ & $\mathrm{Osmolality}^{-}$ \\
\hline 1 & 148 & 4 & 120 & 14 & 2 & 2 & 0 & 7.6 & 290 \\
2 & 148 & 4 & 115 & 14 & 2 & 2 & 5 & 7.55 & 290 \\
\hline
\end{tabular}

Solutions contained $2 \mathrm{mmol}^{-1}$ sodium oxalate labelled with $25 \mu \mathrm{Ci}^{1^{-1}}$ (U-14C) oxalic acid, and also $3 \mathrm{~g} \mathrm{l}^{-1}$ of polyethylene glycol (PEG: M Wt 4000).

Electrolytes-mEq $^{-1}$

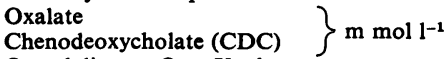

Osmolality-mOsm $\mathrm{Kg}^{-1}$.

aliquots were taken for subsequent analysis of polyethylene glycol (PEG) and ${ }^{14} \mathrm{C}$-oxalate specific activity. The composition of the two perfusion solutions is shown in Table 1. Chemicals were of AR grade. $\left(\mathrm{U}-{ }^{14} \mathrm{C}\right)$ oxalic acid was obtained from the Radiochemical Centre (Amersham, Bucks). Chenodeoxycholic acid was shown to be more than $95 \%$ pure by thin layer chromatography before conversion to the sodium salt. Both subjects were perfused with both solutions, an interval of 48 hours being allowed between one solution and the next. Subject HS was studied twice, the solutions being perfused in the reverse order on the second occasion. Subject CM was studied only once.

The total amount of each solution perfused was recorded and used to calculate the total amount of $\left({ }^{14} \mathrm{C}\right)$ oxalate perfused. At the end of each perfusion study the colon was cleansed of retained perfusion solution by rapid perfusion with physiological saline. Urine passed over the 36 hours after each perfusion was collected in 12 hour aliquots for analysis of $\left({ }^{14} \mathrm{C}\right)$ oxalate.

ANALYTICAL METHOdS AND CALCULATION PEG was measured turbidimetrically by the method of Hyden (1955). Osmolality of solutions was measured by freezing point depression using an Advanced Osmometer (Advanced Instruments, Newton Highlands, Massachusetts, USA). pH was measured using a standard glass electrode. $\left({ }^{14} \mathrm{C}\right)$ radioactivity in perfusion solutions and urine was measured by liquid scintillation counting (Tracerlab Corumatic with an external standard, using toluene containing $4 \mathrm{~g} \mathrm{l}^{-1}$ of 2,5 diphenyloxazole mixed 3:1 with triton X100 as scintillant).

The net disappearance of oxalate from the colonic lumen was calculated by standard formulae (Levitan et al., 1962) and expressed as $\mu$ moles of sodium oxalate disappearing from the colonic lumen per minute. The appearance of $\left({ }^{14} \mathrm{C}\right)$ oxalate in the urine over the 36 hours after perfusion is expressed as percentage of the perfused load of $\left({ }^{14} \mathrm{C}\right)$ oxalate and as the total amount of oxalate ( $\mu$ moles) appearing in the urine over this period.

\section{Results}

DISAPPEARANCE OF OXALATE FROM COLONIC LUMEN

There was a marked increase, by a factor of at least 5 , in the rate of disappearance of oxalate from the colonic lumen when sodium chenodeoxycholate was included in the perfusion solutions (control-range $=0.04$ to $0.96 \mu \mathrm{mol} \mathrm{min}^{-1} ;+\mathrm{CDC}$ range $=5.04$ to $5.54 \mu \mathrm{mol} \mathrm{min}^{-1}$ : Fig. 1).

\section{APPEARANCE OF OXALATE IN URINE}

The percentage of perfused oxalate appearing in urine in the 36 hours after perfusion was increased by a factor of at least 6 when sodium chenodeoxycholate was included in the perfusion solutions (control range $=0.6$ to $2.59 \%+\mathrm{CDC}$ range $=$

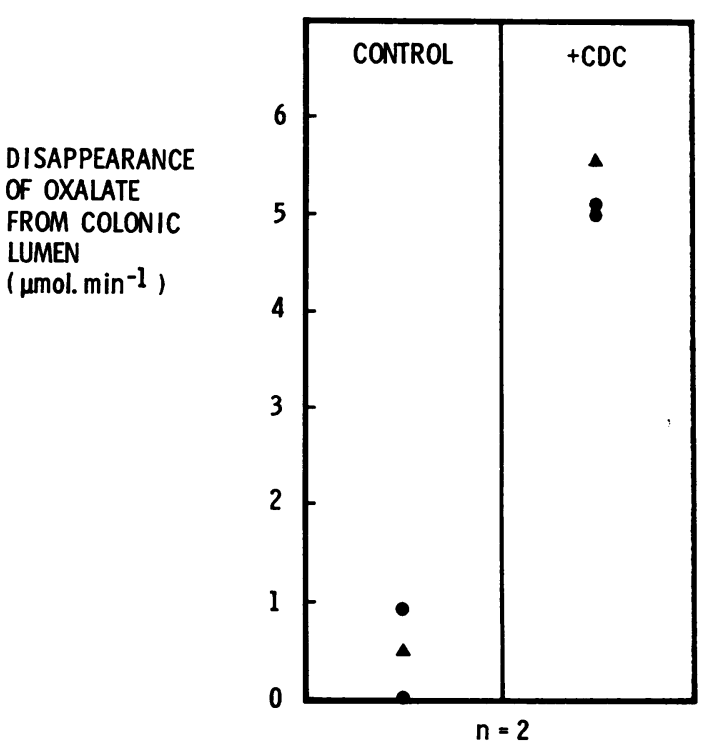

Fig. 1 Disappearance of oxalate from colonic lumen ( $\mu \mathrm{mol} \mathrm{min}^{-1}$ ) during perfusion of excluded colon with control and chenodeoxycholate $(C D C)$ containing solutions. Subject HS. $\triangle$ Subject CM. 


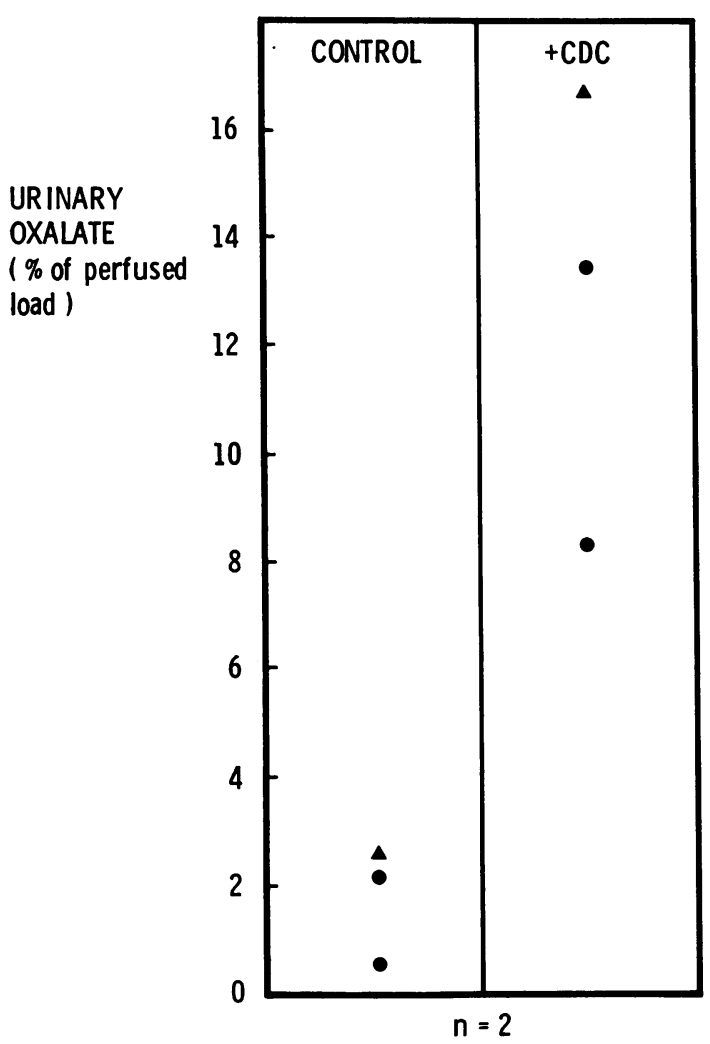

Fig. 2 Appearance of oxalate in the urine (percent of perfused load) in the 36 hours after each colonic perfusion. Subject HS. $\triangle$ Subject CM.

8.3 to $16.6 \%$, Fig. 2). The total amounts of oxalate excreted in this period are shown in Table 2.

Less than $1.1 \%$ of the excreted $\left({ }^{14} \mathrm{C}\right)$ radioactivity appeared in the third 12 hour urine collection in each case, indicating no significant carry-over of urinary oxalate from one perfusion to the next. Postperfusion cleansing of the colon was considered adequate because effluents after cleansing contained less than $10 \%$ of the $\left({ }^{14} \mathrm{C}\right)$ radioactivity of the perfusion solutions.

Table 2 Oxalate appearance in urine in the 36 hours after colonic perfusion with $2 \mathrm{mmol} \mathrm{l}^{-1}$ sodium oxalate, without and with $5 \mathrm{mmol} \mathrm{l}^{-1}$ sodium chenodeoxycholate $(C D C)$

\begin{tabular}{llll}
\hline Subject & & \multicolumn{2}{l}{$\begin{array}{l}\text { Oxalate appearing in urine in } \\
\text { 36 hours after perfusion }(\mu \mathrm{mol})\end{array}$} \\
\cline { 3 - 4 } \cline { 3 - 4 } & & Control & $+C D C$ \\
\hline HS & $(1)$ & 82 & 524 \\
CM & $(2)$ & 16 & 266 \\
& & 83 & 534 \\
\hline
\end{tabular}

Subject HS was studied on two separate occasions.

\section{COLONIC WATER ABSORPTION}

The mean variability of PEG estimations (range/ mean) in the four effluent samples was $2.6 \%$, indicating attainment of an adequate steady-state in each perfusion. Very little water movement occurred during perfusion of solution 1 , whereas the presence of $5 \mathrm{mmol} \mathrm{l}^{-1}$ sodium chenodeoxycholate in solution 2 induced marked water secretion on all occasions (Fig. 3).

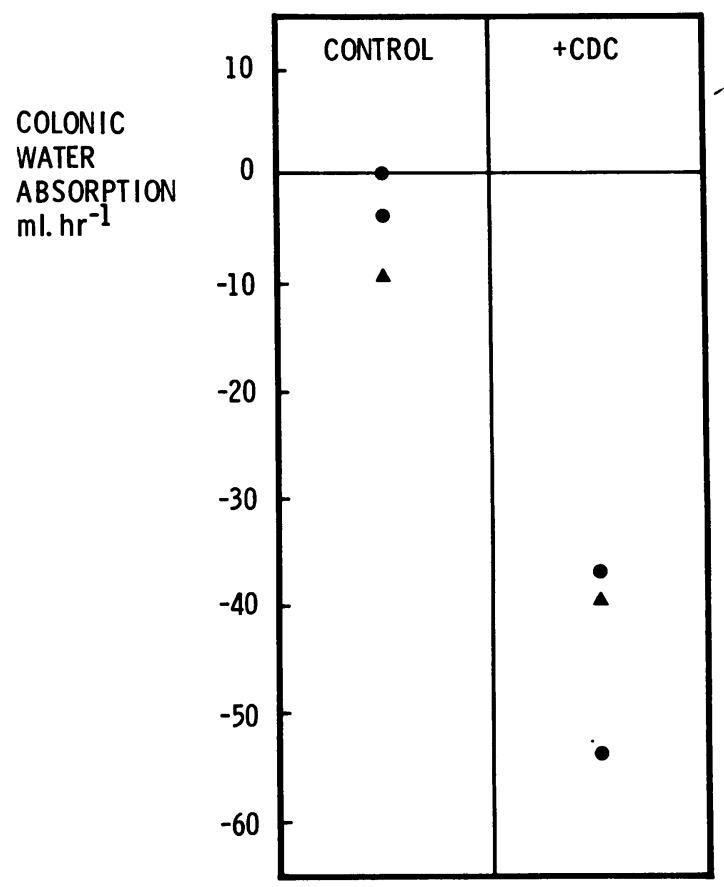

Fig. 3 Colonic water absorption $\left(\mathrm{ml} \mathrm{hr}^{-1}\right)$ during perfusion of control and chenodeoxycholate $(C D C)$ containing solutions. @ Subject HS. $\triangle$ Subject CM.

PH OF LUMINAL CONTENTS

There was no significant change in the $\mathrm{pH}$ of colonic effluents compared to perfusates.

\section{Discussion}

The present study shows unequivocally that oxalate absorption from the excluded colon is increased by the presence in the lumen of an unconjugated bile salt. Normal faeces contain only small amounts of bile salt bound to solid material (Norman, 1964; Findlay et al., 1973) but after ileal resection the colon may be presented with high concentrations of bile salts. The solid residue of faeces from patients 
with ileal resection may contain up to $30 \mathrm{mmol}^{-1}$ of bile salt, and even in the supernatant, bile salt concentrations may reach $13 \mathrm{mmol} \mathrm{l}^{-1}$ (Mitchell et al., 1973; Hofmann and Poley, 1972). The concentration of bile salt used in the present study is therefore appropriate. Estimates of the oxalate content of a normal diet vary between approximately $1 \mathrm{mmol} / 24 \mathrm{~h}$ (Zarembski and Hodgkinson, 1962) to approximately $10 \mathrm{mmol} / 24 \mathrm{~h}$ (Archer et al., 1957); the lower value is generally agreed to be the more likely. In normal subjects only about $5 \%$ of oxalate taken in the diet is absorbed (Archer et al., 1957; Earnest et al., 1974) and, as ileal input into the colon is of the order of 1 to 2 litres per day (Devroede and Phillips, 1969), a concentration of oxalate in the colonic lumen of $2 \mathrm{mmol} \mathrm{I}^{-1}$ is likely to be approximately physiological. Whether, however, in the in vivo situation this is all present as the soluble sodium salt is uncertain.

It may be argued that the excluded colon does not function normally. Bown et al. (1972), using a similar perfusate to solution 1 of the present study, showed that water and electrolyte absorption from the excluded colon was similar to that reported in perfusion studies of the intact colon in normal subjects (Levitan et al., 1962). However, during perfusion of solution 1 in the present study there was no significant absorption of water from the excluded colons of our two subjects. This is probably due to vigorous cleansing of the colon with saline washouts and might have been obviated by allowing a longer period for mucosal recovery. While it is possible that the demonstrated effect of chenodeoxycholate on colonic oxalate absorption is seen only under these conditions, this does not seem likely. Even allowing for an increase in mucosal permeability, only small amounts of oxalate were absorbed in the absence of bile acid. Chenodeoxycholate also induced the expected water secretion (Mekhjian et al., 1971). The influence of bacterial flora on oxalate absorption is unknown. However, it seems unlikely that a change in flora can account for the present results, because the flora of the excluded colon has been shown to be substantial and qualitatively similar to that of faeces (Vince et al., 1973). These facts suggest that the function of these excluded colons is not radically different from normal.

The mechanism of increased oxalate absorption after ileal resection is uncertain, and may be multifactorial. Attention has focused largely on changes in intraluminal constituents and their influence on intraluminal calcium concentrations (Stauffer et al., 1974). A correlation has been found between fat malabsorption and hyperoxaluria (Earnest et al., 1974; McDonald et al., 1975). It has been suggested that this effect is due to binding of calcium by fats, leaving more oxalate in solution available for absorption; some success has been reported in controlling hyperoxaluria by reducing the fat content of the diet (Andersson and Jagenburg, 1974).

In the experiments described in this paper, calcium was not present in the perfusate, so the changes in oxalate absorption cannot be explained by changes in intraluminal calcium ion concentration. In the control experiment, absorption of perfused oxalate was less than $5 \%$, suggesting that even in conditions approximating to the fasting state with low intraluminal calcium concentrations, oxalate absorption by the colon is very low. On additon of sodium chenodeoxycholate $5 \mathrm{mmol}^{-1}$ colonic absorption of oxalate was increased five- to 10 -fold.

If spillage of bile salts into the colon of patients with ileal resection has an effect similar to chenodeoxycholate in our perfusion studies, the demonstrated increase in colonic oxalate absorption would be sufficient to account for hyperoxaluria in intestinal disease. The beneficial effect of cholestyramine in reducing oxaluria in these cases may be due as much to its bile salt binding effect as to binding of oxalate in the intestinal lumen (Smith et al., 1972; Stauffer et al., 1973).

It has been shown that oxalate is absorbed from the rat intestine by passive diffusion (Binder, 1974) and that deoxycholic acid increases both colonic oxalate absorption and mucosal permeability for urea (Chadwick et al., 1974; Dobbins and Binder, 1975 ) in the rat. It seems likely that altered mucosal permeability is also the explanation for our findings in the excluded colon of man. As raised levels of bile acids in faeces have also been shown in children with pancreatic insufficiency due to cystic fibrosis and to pancreatic hypoplasia (Weber et al., 1973) and after small bowel bypass (Moore et al., 1969), this may also be the explanation for the hyperoxaluria in these groups of patients. It remains possible that luminal long chain fatty acids-which of themselves increase colonic mucosal permeability (Dobbins and Binder, 1975) and may bind calcium ions in the gut (Binder, 1974) also play a part in the production of secondary hyperoxaluria in intestinal disorders.

It is a pleasure to acknowledge help and constructive criticism from Dr A. M. Dawson, and financial support from the Joint Research Board of St. Bartholomew's Hospital and the North East Thames Area Health Authority.

\section{References}

Admirand, W. H., Earnest, D. L., and Williams, H. E. (1971). Hyperoxaluria and bowel disease. Transactions of the Association of American Physicians, 84, 307-312. 
Andersson, H., and Jagenburg, R. (1974). Fat-reduced diet in the treatment of hyperoxaluria in patients with ileopathy. Gut, 15, 360-366.

Archer, H. E., Dormer, A. E., Scowen, E. F., and Watts, R. W. E. (1957). Studies on the urinary excretion of oxalate by normal subjects. Clinical Science, 16, 405-411.

Binder, H J. (1974). Intestinal oxalate absorption. Gastroenterology, 67, 441-446.

Bown, R. L., Sladen, G. E., Rousseau, B., Gibson, J. A., Clark, M. L., and Dawson, A. M. (1972). A study of water and electrolyte transport by the excluded human colon. Clinical Science, 43, 891-902.

Chadwick, V. S., Modha, K., and Dowling, R. H. (1973). Mechanism of hyperoxaluria in patients with ileal dysfunction. New England Journal of Medicine 289, 172-176.

Chadwick, V. S., Elias, E., Bell, G. D., and Dowling, R. H. (1974). The role of bile acids in the increased intestinal absorption of oxalate after ileal resection. In Advances in Bile Acid Research. III. Bile Acid Meeting. Edited by S. Matern, J. Hackenschmidt, P. Back, and W. Gerok. Schattauer: Stuttgart.

Devroede, G. J., and Phillips, S. F. (1969). Studies of the perfusion technique for colonic absorption. Gastroentero$\log y, 56,92-100$.

Dickstein, S. S., and Frame, B. (1973). Urinary tract calculi after intestinal shunt operations for the treatment of obesity. Surgery, Gynecology, and Obstetrics, 136, 257-260.

Dobbins, J., and Binder, H. J. (1975). Bile salts and hydroxy fatty acids increase colonic oxalate absorption, a possible mechanism for hyperoxaluria? Gastroenterology, 68, 864. (Abstr.)

Dowling, R. H., Rose, G. A., and Sutor, D. J. (1971). Hyperoxaluria and renal calculi in ileal disease. Lancet, 1 , 1103-1106.

Earnest, D. L., Johnson, G., Williams, H. E., and Admirand, W. H. (1974). Hyperoxaluria in patients with ileal resection. An abnormality in dietary oxalate absorption. Gastroenterology, 66, 1114-1122.

Findlay, J. M., Eastwood, M. A., and Mitchell, W. D. (1973). The physical state of bile acids in the diarrhoeal stool of ileal dysfunction. Gut, 14, 319-323.

Hofmann, A. F., and Poley, J. R. (1972). Role of bile acid malabsorption in pathogenesis of diarrhea and steatorrhea in patients with ileal resection. Gastroenterology, 62, 918-934.

Hyden, S. (1955). A turbidimetric method for the determination of the higher polyethylene glycols in biological materials. Annals of the Agricultural College of Sweden, 22, 139-145.

Levitan, R., Fordtran, J. S., Burrows, B. A., and Ingelfinger,
F. J. (1962). Water and salt absorption in the human colon. Journal of Clinical Investigation, 41, 1754-1759.

McDermott, W. V., Victor, M., and Point, W. W. (1962). Exclusion of the colon in the treatment of hepatic encephalopathy. New England Journal of Medicine, 267, 850-854. McDonald, G. B., Earnest, D. L., and Admirand, W. H. (1975). Hyperoxaluria correlates with steatorrhea in patients with celiac sprue. Gastroenterology, 68, 949. (Abstr.).

Mekhjian, H. S., Phillips, S. F., and Hofmann, A. F. (1971). Colonic secretion of water and electrolytes induced by bile acids; perfusion studies in man. Journal of Clinical Invest $i$ gation, 50, 1569-1577.

Mitchell, W. D., Findlay, J. M., Prescott, R. J., Eastwood, M. A., and Horn, D. B. (1973). Bile acids in the diarrhoea of ileal resection. Gut, 14, 348-353.

Moore, R. B., Frantz, I. D., and Buchwald, H. (1969). Changes in cholesterol pool size, turnover rate and fecal bile acid and sterol excretion after partial ileal bypass in hypercholesteremic patients. Surgery, 65, 98-108.

Norman, A. (1964). Faecal excretion products of cholic acid in man. British Journal of Nutrition, 18, 173-186.

O'Leary, J. P., Thomas, W. C., Jr, and Woodward, E. R. (1974). Urinary tract stone after small bowel bypass for morbid obesity. American Journal of Surgery, 127, 142-147

Smith, L. H., Fromm, H., and Hofmann, A. F. (1972). Acquired hyperoxaluria, nephrolithiasis and intestinal disease. New England Journal of Medicine, 286, 1371-1375.

Smith, L. H., Hofmann, A. F., McCall, J. T. and Thomas, P. J. (1970) Secondary hyperoxaluria in patients with ileal resection and oxalate nephrolithiasis. Clinical Research, 18, 541. (Absts).

Stauffer, J. Q., Humphreys, M. H., and Weir, G. J. (1973). Acquired hyperoxaluria with regional enteritis after ileal resection: role of dietary oxalate. Annals of Internal Medicine, 79, 383-391.

Stauffer, J. Q., Stewart, R. J., and Bertrand, G. (1974). Acquired hyperoxaluria: relationship to dietary calcium content and severity of steatorrhea. Gastroenterology, 66, 783. (Abstr.)

Vince, A., Bown, R., O'Grady, F., and Dawson, A. M. (1973). The effect of perfusion on the flora of the excluded colon. Gut, 14, 178-182.

Weber, A. M., Roy, C. C., Morin, C. L., and Lasalle, R. (1973). Malabsorption of bile acids in children with cystic fibrosis. New England Journal of Medicine, 289, 1001-1005.

Zarembski, P. M., and Hodgkinson, A. (1962). The oxalic acid content of English diets. British Journal of $N$ 'strition, 16, 627-634. 